\title{
The phosphatases of peripheral white blood cells in workers exposed to trichloroethylene and perchloroethylene
}

\author{
ALŽBĚTA FRIBORSKÁ \\ Department of Occupational Diseases of the University Polyclinic, Prague, Czechoslovakia
}

Friborská, A. (1969). Brit. J. industr. Med., 26, 159-161. The phosphatases of peripheral white blood cells in workers exposed to trichloroethylene and perchloroethylene. The activity of leucocyte alkaline phosphatase was found to be increased in people continuously exposed during their working hours to trichloroethylene. The increase correlated with the severity of exposure. Possible causes are discussed. The activity of acid phosphatases was also increased. Periodic acid Schiff reaction staining (with and without diastase digestion) gave no pathological results.

The activity of alkaline phosphatase in human neutrophilic leucocytes (L.A.P.) depends upon, among other things, heredity factors (SantachiaraBenerecetti, Cesari, and De Carli, 1967; Winkelstein, Goldberg, Tishkoff, and Sparkes, 1967; Gropp, Fischer, Niederalt, Klesse, and Hensen, 1968), pathological conditions, e.g., hypophosphataemia (Beisel, Benjamin, and Austen, 1959), the excretory system (Griffin and Cox, 1966; Rosner and Lee, 1965), and the relationship between serum and leucocyte alkaline phosphatases (Lohmann and Weissel, 1964). Many papers have dealt with L.A.P. activity in various diseases, the levels found being important in diagnosis (Sigg, 1966). As phosphatases are important basic enzymes I have investigated the activity of alkaline and acid phosphatases in the white blood cells of people exposed to trichloroethylene or to perchloroethylene (tetrachloroethylene) or to both.

\section{Materials and methods}

In this work 23 people exposed to trichloroethylene, seven exposed to perchloroethylene, and four exposed to both were studied. All were exposed continuously during work. Every subject was given a clinical examination to eliminate those suffering from illnesses which could influence phosphatase levels (diabetes, liver disease, and pregnancy). A control group of healthy, unexposed volunteers was also investigated.

Exposure was estimated by determining urinary trichloroacetic acid by a modification of the Fujiware method (Souček and Franklová, 1952) and trichloroethanol as described by Vlachová (1956), also by taking into consideration the condition of the working environment. From the concentrations of trichloroacetic acid in their urine the workers exposed to trichloroethylene were divided into three groups. Those whose urines contained at least $100 \mathrm{mg}$. trichloroacetic acid per litre were the most heavily exposed, and were graded +++ ; those whose urines contained 50 to $100 \mathrm{mg}$. per litre were graded ++ ; and those whose urines contained 0 to $50 \mathrm{mg}$. per litre were graded + .

Alkaline phosphatases were stained and scored by the method of Kaplow (1963), modified as described by Hayhoe and Quaglino (1958). The periodic acid Schiff reaction (P.A.S.) was performed with and without diastase digestion, as described by Rosenszajn, Marshak, and Efrati (1963).

\section{Results}

\section{Trichloroethylene}

In the 20 controls the L.A.P. levels ranged from 35 to 95 with a mean value of 58 . These levels were similar to those found by Hausser and Stroun (1962), Kaplow (1955), Knoblauch (1962), and Merker and 


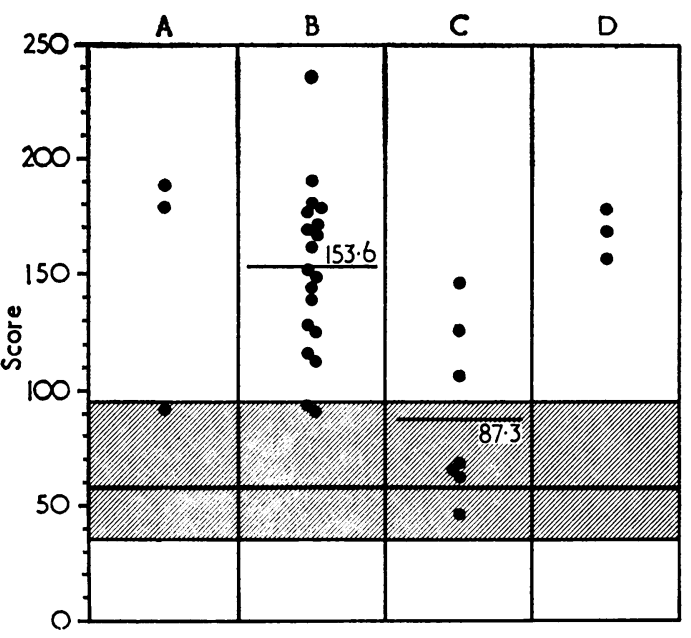

$A=$ Group exposed to trichloroethylene $(++)$

$B=$ Group exposed to trichloroethylene $(+++)$

$C=$ Group exposed to perchloroethylene

$D=$ Group exposed to trichloroethylene and perchloroethylene

FIGURE. Leucocyte alkaline phosphatase activity in controls and in workers exposed to trichloroethylene, perchloroethylene or both. The mean level in 20 controls is shown by the horizontal bar, and the hatched area indicates the range of values in this group.

Heilmeyer (1960), and confirmed that, in people without exposure, L.A.P. levels rarely exceed 100 .

In nearly all those with medium $(++)$ or heavy $(+++)$ exposure the phosphatase activity was higher than normal (Figure). Subjects were investigated several times, and when their L.A.P. scores did not differ much only the mean values are given. There was only one person with a low $(+)$ exposure and his L.A.P. score (49) was essentially normal.

Two cases illustrate the effects of interrupted exposures:

1. A 39-year-old man had medium exposure for six months, and his L.A.P. score was 50. The exposure then increased considerably, he developed signs of poisoning, and his urine contained $383 \mathrm{mg}$. of trichloroacetic acid per litre and $493 \mathrm{mg}$. of trichloroethanol per litre, providing confirmation of a very heavy exposure, and his L.A.P. score rose to 147. He was removed from work for two weeks. After he had been back at work for two days his urine contained $42 \mathrm{mg}$. of trichloroacetic acid per litre and $60 \mathrm{mg}$. of trichloroethanol per litre, corresponding to low $(+)$ exposure, but his L.A.P. score remained elevated at 150 .

2. A 48-year-old man worked for four weeks after a three-month break. His urine contained 84 mg. of trichloroacetic acid per litre and $123 \mathrm{mg}$. of trichloroethanol per litre $(++)$, but his L.A.P. was essentially normal (score 64). After six weeks' further exposure followed by a two-week holiday his urine contained little trichloroacetic acid or trichloroethanol $(13 \mathrm{mg}$. per litre and $0 \mathrm{mg}$. per litre respectively) and his L.A.P. score had fallen a little to 46. After further work at heavy exposure $(+++)$ his L.A.P. score rose to 167.

\section{Perchloroethylene}

The L.A.P. scores were sometimes raised (Figure) but the mean was within the normal range.

Trichloroethylene and perchloroethylene

The L.A.P. scores were raised as in those heavily exposed to trichloroethylene alone (Figure).

\section{Acid phosphatase}

The scores were raised in all subjects exposed to trichloroethylene, and in two of the subjects exposed to perchloroethylene alone. The P.A.S. reaction was positive in all cases, and after diastase digestion the magenta colour disappeared.

In the controls the scores agreed with those found by Rosenszajn and his colleagues (1963).

\section{Discussion}

The activity of L.A.P. is increased in many conditions and can be explained as a defence mechanism against bacterial infections, etc. The enzyme plays an active part in phagocytosis (Merker, 1963). The relationship between malignant tumours, cytostatic treatment, and the activity of L.A.P. suggests a relationship between the effectiveness of the defence mechanisms and the activity of L.A.P. Osten (1966) demonstrated a temporary decrease in the activity of L.A.P. during cytostatic treatment, which was, however, followed by an increase in L.A.P. activity in those cases with better prognosis. The opposite was true for unfavourable cases. The findings of Lorbacher, Fischer, and Schmähl (1963), who studied experimental tumours in rats, were more equivocal.

Apart from defence mechanisms local phenomena may affect the L.A.P. scores. Vanotti (1963) pointed out the significance of the $p \mathrm{H}$ of the blood which may be affected during the metabolism of trichloroethylene.

Melnykovych, Bishop, and Swayze (1967) described their findings on L.A.P. in cell cultures under the influence of hormones. They noted difficulty in interpreting their results 'because of the lack of information about the physiological role of alkaline phosphatase which, because of its broad substrate specificity, can break down many important metabolic intermediates including mononucleotides, esters of primary and secondary alcohols and phenols'. This suggests that L.A.P. may have some function in the detoxication of trichloroethylene.

A connexion between increased activity of L.A.P. 
and exposure to trichloroethylene has been demonstrated in this paper. It is noteworthy that after a prolonged absence from work the excretion of metabolites decreased as did the activity of L.A.P. The changes in the level of trichloroacetic acid in urine and the activity of L.A.P. were not, however, concomitant. L.A.P. scores rise more slowly and remain elevated for longer than the levels of trichloroacetic acid. This phenomenon is similar to the relationship of fever and leucocytosis with L.A.P. in the pyrexia experiments described by Merker (1963; 1965).

An interpretation of the increased activity of acid phosphatase is difficult. The P.A.S. reaction (with and without diastase digestion) did not indicate a pathological condition, so presumably there was no disorder in glycogen metabolism (Gahrton, 1966; Wulff, 1967).

The skilful technical co-operation of Marie Volejniková is acknowledged.

\section{References}

Beisel, W. R., Benjamin, N., and Austen, K. F. (1959). Absence of leukocyte alkaline phosphatase activity in hypophosphatasia. Blood, 14, 975-977.

Gahrton, G. (1966). The periodic acid-Schiff reaction in neutrophil leukocytes in untreated and Myleran-treated chronic myelocytic leukemia. A quantitative microspectrophotometric study. Ibid., 28, 544-552.

Griffin, M. J. and Cox, R. P. (1966). Studies on the mechanism of hormone induction of alkaline phosphatase in human cell cultures. II. Rate of enzyme synthesis and properties of base level and induced enzymes. Proc. nat. Acad. Sci. (Wash.), 56, $946-953$.

Gropp, A., Fischer, R., Niederalt, G., Klesse, M. P., and Hensen, S. (1968). Philadelphia-Chromosom und alkalische LeukocytenPhosphatase bei chronischer Myelose. Klin. Wschr., 46, 177-187.

Hausser, E., and Stroun, J. (1962). La phosphatase alkaline leucocytaire au cours des affections virales. Schweiz. med. Wrchr., 92, 1334-1335.

Hayhoe, F. G. J., and Quaglino, D. (1958). Cytochemical demonstration and measurement of leucocyte alkaline phosphatase activity in normal and pathological states by a modified azo-dye coupling technique. Brit. J. Haemat., 4, 375-389.
Kaplow, L. S. (1955). A histochemical procedure for localizing and evaluating leukocyte alkaline phosphatase activity in smears of blood and marrow. Blood, 10, 1023-1029.

(1963). Cytochemistry of leukocyte alkaline phosphatase. Amer. J. clin. Path., 39, 439-449.

Knoblauch, M. (1962). Uber die alkalische Phosphatase in neutrophilen Leukocyten. Helv. med. Acta, 29, 143-155.

Lohmann, D., and Weissel, M. (1964). Die Abhängikeit der alkalischen Leukocytenphosphatase von Plasmafaktoren. Klin. Wschr., 42, 245.

Lorbacher, P., Fischer, R., and Schmähl, D. (1963). Uber das Verhalten der alkalischen Leukocaten-phosphatase bei experimentellen Tiertumoren. In Zyto- und Histochemie in der Hämatologie: IX. Freiburger Symposium, 1963. Pp. 320-328. Ed. H. Merker. Springer, Berlin.

Melnykovych, G., Bishop, C. F., and Swayze, M. A. B. (1967). Fluctuation of alkaline phosphatase activity in synchronized heteroploid cell cultures: effects of prednisolone. J. cell. Physiol., 70, 231-236.

Merker, H. (1963). Grundlagen zur klinisch-morphologischen Blutdiagnostik mit Hydrolasen. Discussion, p. 252. In IX. Freiburger Symposium, 1963. Ed. H. Merker. Springer, Berlin.

- (1965). Die alkalische Leukozytenphosphatase-ihre hämatologische and allgemeinklinische Bedeutung. Dtsch. med. Wschr., 90, 484-486.

—, and Heilmeyer L. (1960). Die alkalische Phosphatase neutrophiler Leukozyten. Dtsch. med. Wschr., 85, 253-258.

Osten, W. (1966). Glutamat-Dehydrogenase und alkalische Phosphatase in Leukozyten von Krebskranken. Med. Klin., 61, 1776-1982.

Rosner, F., and Lee, S. L. (1965). Endocrine relationships of leukocyte alkaline phosphatase. Blood, 25, 356-369.

Rosenszajn, L., Marshak, G., and Efrati, P. (1963). Acid phosphatase activity in normal human blood and bone marrow cells as demonstrated by the azo dye method. Acta haemat (Basel), 30, 310-316.

Santachiara-Benerecetti, S. A., Cesari, I., and De Carli, L. (1967). Some properties of alkaline phosphatase from a human cell strain and from a clonal derivative with low activity. J. Cell. Physiol., 69, $169-176$

Sigg, R. H. (1966). Die semiologische Bedeutung cytochemischer Untersuchungen an Leukocyten. Schweiz. med. Wschr., 96, $654-660$.

Soucek, B., and Franklová, E. (1952). The estimation of small quantities of trichloroethylene and trichloroacetic acid. (Czech.). Pracov. Lexk., 4, 264-272.

Vanotti, A. (1963). Discussion to lecture by Schmähl. In IX. Freiburger Symposium, 1963, p. 272. Ed. H. Merker. Springer, Berlin.

Vlachová, D. (1956). A simple method for the determination of trichloroethanol in urine (Czech.). Pracov LXk., 8, 433-435.

Winkelstein, A., Goldberg, L. S., Tishkoff, G. H., and Sparkes, R. S. (1967). Leukocyte alkaline phosphatase and the Philadelphia chromosome. Arch. intern. Med., 119, 291-296.

Wulff, H. R. (1967). Morphological and Histological Features of Leucocytes in Experimental Inflammation and in Disease. Munksgaard, Copenhagen.

Received for publication July 1, 1968. 